\title{
Extracellular Production of Human Tumor Necrosis Factor- $\alpha$ by Escherichia coli Using a Chemically-synthesized Gene
}

\author{
Satoshi Nakamura, ${ }^{*}+\dagger$ Tsukio Masegi, Kazuo KitaI, \\ Yataro ICHIKAwA, Toshiaki Kudo, ${ }^{* *}$ Rikizo AONO* \\ and Koki HoRIKOSHI ${ }^{* * * *}$ \\ Biotechnology Research Laboratories, Teijin Limited, Hino-shi, Tokyo 191, Japan \\ * Department of Bioengineering, Tokyo Institute of Technology, \\ Meguro-ku, Tokyo 152, Japan \\ ** The Riken Institute, Wako-shi, Saitama 351-01, Japan
}

Received June 18, 1990

\begin{abstract}
A DNA fragment of approximately 490 base pairs encoding human TNF was chemically synthesized and expressed within Escherichia coli cells. Furthermore, extracellular production of human TNF and several N-terminal deletion mutants of TNF was attempted using the excretion vector pEAP8. The TNF mutant with two $\mathrm{N}$-terminal amino acids deleted (N $\triangle 2$-TNF) was efficiently excreted into the culture medium by $E$. coli carrying the plasmid pEXTNF3. In this clone, the signal peptide was correctly processed during the excretion. The $E$. coli-excreted N 42 -TNF had higher antitumor activity than wild-type TNF or N $\Delta 2$-TNF produced intracellularly by $E$. coli.
\end{abstract}

Tumor necrosis factor- $\alpha$ (TNF) was identified by Carswell et al. ${ }^{1)}$ in the serum of mice infected with Bacillus Calmett-Guerin and subsequently treated with endotoxin. Since TNF has been found to cause hemorrhagic necrosis of Meth A sarcoma and other transplantable tumors without destroying normal tissues, this substance appears highly promising as an anticancer agent.

The gene for human TNF has now been cloned and expressed in Escherichia coli, ${ }^{2-6)}$ making large quantities of pure TNF available for clinical trials in patients with advanced cancer. However, the TNF which is produced within $E$. coli cells has failed to provide satisfactory anticancer effects when administered alone, particularly by systemic administration. This is largely due to the fact that the dose required for the anticancer effect is very close to the toxic level, and therefore adequate quantities cannot be safely administered. On the other hand, before the availability of recombinant TNF, basic experi- ments had been done using natural TNF produced by stimulation of animals other than man. In those systems, no toxicity of TNF was observed, and a wide gap between the effective and toxic doses was documented. ${ }^{7)}$ Thus, TNF produced within E. coli cells and natural TNF display widely different activities, and one reason for this may be differences in the tertiary structures of the two substances. ${ }^{7,8)}$

We have bred a strain of $E$. coli producing extracellularly the $\mathrm{Fc}$ region protein of human immunoglobulin $G_{1}$ by weak activation of the kil gene, which is present in a dormant state in the plasmid pMB9. ${ }^{9}$ This Fc protein, when produced intracellularly by $E$. coli, assumes a monomeric form. ${ }^{10,11)}$ However, extracellularly-excreted Fc protein is dimeric, joined by disulfied bonds at the hinge region, ${ }^{9)}$ and resembles natural $\mathrm{Fc}$ protein with respect to its tertiary structure and functional aspects. ${ }^{12)}$ The above facts suggest that extracellular production may constitute an effective means of obtaining a suitable tertiary structure for

$\dagger$ Correspondence to: S. Nakamura, Department of Bioengineering, Faculty of Bioscience and Biotechnology, Tokyo Institute of Technology, O-okayama, Meguro-ku, Tokyo 152, Japan. 
microbially-produced proteins.

In this study, a DNA fragment of approximately 490 base pairs (bp) encoding human TNF was designed and chemically synthesized, and then this synthetic gene was expressed intracellularly in E. coli. Furthermore, with a view to obtaining recombinant TNF with a tertiary structure closer to that of natural TNF, extracellular production of wild-type TNF as well as TNF mutants with various amino terminus (N-terminus) deletions was attempted. One of these, a TNF mutant with a deletion of the two amino acids at the $\mathrm{N}$-terminus (N口2-TNF), was efficiently excreted into the culture medium by $E$. coli cells. The biological characteristics of this excreted N 2 2-TNF were also investigated.

\section{Materials and Methods}

Bacterial strains and plasmids. The hosts used in these studies were E. coli C600r ${ }^{-} \mathrm{m}^{-}$(ATCC 33525) and E. coli HB101 (ATCC 33694).

The vector used for intracellular expression was pAA4 $1,{ }^{11)}$ while pEAP8 ${ }^{13}$ ) was used for extracellular expression.

Chemical synthesis of DNA and cloning techniques. Oligonucleotides were synthesized using a Model 380A DNA synthesizer (Applied Biosystems). Synthesized oligonucleotides were purified by polyacrylamide gel electrophoresis (PAGE).

The cloning techniques used were as described in the manual by Maniatis et al. ${ }^{14 \text { ) }}$

Analysis of TNF gene expression. E. coli with extracellular expression plasmids was cultivated at $37^{\circ} \mathrm{C}$ for at least $24 \mathrm{hr}$ in LB medium $(0.5 \%$ yeast extract, $1 \%$ tryptone, and $1 \%$ sodium chloride; $\mathrm{pH} 7.2$ ). Fractionation of the extracellular, periplasmic, and cytoplasmic fractions of the culture material was done by the method of Kato et al. ${ }^{13)}$ Each fraction was concentrated by the acetone precipitation method.

E. coli with intracellular expression plasmids was inoculated into M9 medium ${ }^{14)}$ containing $1 \%$ casamino acids, $1 \%$ glucose, and $30 \mu \mathrm{g} / \mathrm{ml}$ ampicillin. The cells were cultured at $37^{\circ} \mathrm{C}$ until the optical density at $600 \mathrm{~nm}$ reached 0.7 ; then, after adding $50 \mu \mathrm{g} / \mathrm{ml}$ of indoleacrylic acid, the culture was continued overnight at $37^{\circ} \mathrm{C}$. After the end of this incubation period, the bacteria were pelleted by centrifugation, the cells were disrupted by sonication, and the cell debris was removed by centrifuging to form a lysate, which corresponded to the cytoplasmic fraction of
E. coli harboring extracellular expression plasmids.

The sample fractions thus obtained were electrophoresed on a sodium dodecylsulfate-polyacrylamide gel (SDSPAGE) ${ }^{15 \gamma}$ at a gel concentration of $15 \%$ under reducing conditions, and the proteins in the gel were transferred to nitrocellulose filters by the Western blotting method. ${ }^{16)}$ The TNF proteins on nitrocellulose filters were specifically stained by the indirect method, using anti-human TNF monoclonal antibody ${ }^{17)}$ and an Immunblot kit (Bio-Rad). TNF was also detected by the sandwich solid-phase enzyme-linked immunosorbent assay (ELISA) technique, using two types of anti-human TNF monoclonal antibodies and purified human TNF intracellularly produced by $E$. coli as a control.

Purification of TNF produced by E. coli. The culture supernatants or lysates of $E$. coli carrying expression plasmids were put on an affinity column coupled with anti-human TNF monoclonal antibody. TNF was eluted from the column with a $3 \mathrm{M}$ sodium thiocyanate solution (pH 7.0).

The amino acid composition of the purified TNF was analyzed with a PICO-TAG amino acid analysis system (Waters), and the amino acid sequence of the $\mathrm{N}$-terminus was identified with a Model $470 \mathrm{~A}$ amino acid sequencer (Applied Biosystems).

Assessment of antitumor activity. The in vitro antitumor activity of each sample containing $E$. coli-produced TNF was assayed by the method of Ruff and Gifford, ${ }^{18)}$ using murine L929 cells (ATCC CCL-929). One unit (U) was defined as the quantity of TNF required to kill $50 \%$ of a sample of $4 \times 10^{4}$ cells in the presence of actinomycin D in $18 \mathrm{hr}$.

In vivo activity was assayed by the method of Carswell et al. ${ }^{1)}$ In brief, $5 \times 10^{5}$ murine Meth A sarcoma cells ${ }^{19)}$ were suspended in $50 \mu$ l of RPMI1640 medium (Flow Laboratories) and subcutaneously transplanted to the lateral abdomen of BALB/c mice (male; $6-8$ weeks of age) (Charles River). Seven to ten days after transplantation, when the tumor had grown to a diameter of $6-8 \mathrm{~mm}, E$. coli-produced TNF was injected into the caudal vein, and the degree of hemorrhagic necrosis in the tumors was assessed after $24 \mathrm{hr}$ by the method of Carswell et al. ${ }^{1)}$

\section{Results}

Chemical synthesis of TNF gene and its intracellular expression in $E$. coli

The synthetic gene encoding human TNF was designed by selecting appropriate codons corresponding to the amino acid sequence of human TNF protein, ${ }^{2)}$ and then constructed by chemically synthesizing this sequence of codons. When designing this synthetic TNF 


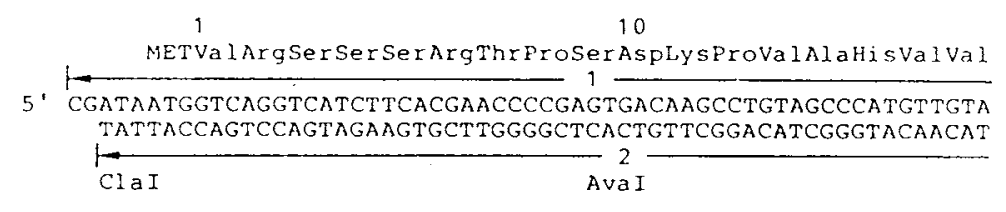

20

30

40

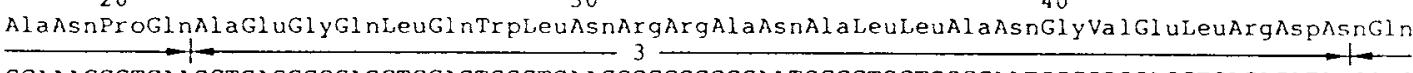
GCAAACCCTCAAGCTGAGGGGCAGCTCCAGTGGCTGAACCGCCGGGCCAATGCCCTGCTGGCCAATGGCGTGGAGCTGAGAGATAACCAO CGTTTGGGAGTTCGACTCCCCGTCGAGGTCACCGACTTGGCGGCCCGGTTACGGGACGACCGGTTACCGCACCTCGACTCTCTATTCGTC Coll

50

60

70

Leuva IVal ProserGiugiyLeuTyrLeuIl eTyrSerGinval LeuPhelysGlyGlnGlyCysProserThrHisValLeuLeuThr CTGGTGGTACCATCAGAGGGCTTGTACCTCATTTACTCCCAGGTCCTCTTCAAGGGCCAAGGCTGCCCGTCGACCCATGTGCTCCTCACC GACCACCATGGTAGTCTCCCGAACATGGAGTAAATGAG IGTCCAGGAGAAGTTCCCGGTTCCGACGGGCAGCTGGGTACACGAGGAGTGG PvuII KpnI

80

90

100

Hi sThrIleSerArgI leAlaVal SerTyrGInThrLysVal AsnLeuLeuSerAlaIleLysSerProCysGlnArgGluThrproGlu 8 $-1$

CACACCATCAGCCGCATCGCCGTCTCCTACCAGACCANGGTCAACCTCCTCTCTGCGATCAAGAGCCCCTGCCAGAGGGAGACCCCAGAG GTGTGGTAGTCGGCGTAGCGGCAGAGGATGGTCTGGTTCCAGTTGGAGGAGAGACGCTAGTTCTCGGGGACGGTCTCCCTCTGGGGTCTC 19

110

120

130

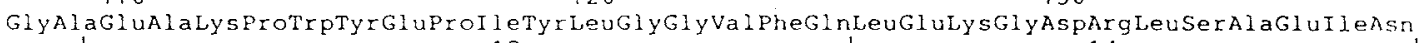
GGGGCTGAGGCCAAGCCATGGTATGAGCCCATCTATCTGGGAGGGGTCTTCCAGCTGGAGAAGGGTGACCGACTCAGCGCTGAAATCANT CCCCGACTCCGGTTCGGTACCATACTCGGGTAGATAGACCCTCCCCAGAAGGTCGACCTCTTCCCACTGGCTGAGTCGCGACTTTAGTTA $\frac{\text { NCOI }}{\text { NCO }} 13 \frac{\text { PVuII }}{\text { BStEII HaeII }}$

140

150

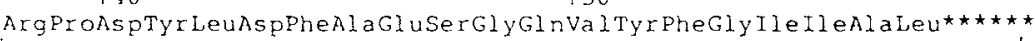

CGGCCCGACTATCTCGACTTTGCCGAGTCTGGGCAGGTCTACTTTGGGATTATTGCCCTGTGATA

GCCGGGCTGATAGAGCTGAAACGGCTCAGACCCGTCCAGATGAMACCCTAATAACGGGACACTATTCGA-5.

$\longrightarrow$

HindII

Fig. 1. DNA Sequence of the Synthetic Human TNF- $\alpha$ Gene.

Arrows indicate the positions of the oligonucleotides 1-17 used to assemble the TNF- $\alpha$ gene. The amino acid sequence and restriction endonuclease cleavage sites are shown above and below the DNA sequence, respectively.

gene, the previously reported DNA sequence of human TNF $\mathrm{cDNA}^{2)}$ was regarded as the fundamental structure, and suitable restriction enzyme cleavage sites were established to facilitate subsequent cloning procedures and gene modifications. Also, a translation initiation codon (ATG) and tendem stop codon (TGA-TAG) were added upstream to the $5^{\prime}$ end and downstream to the 3 -end, respectively, so that the resulting reading frames coincided. The DNA sequence of the TNF gene designed in this manner is shown in Fig. 1.

A DNA fragment consisting of approximately 490 bp was chemically synthesized in separate portions of 17 single-stranded oligonucleotides of approximately $40-70$ bases each (Fig. 1). After purification, these synthetic oligonucleotides were kinated, annealed, and ligated separately in three parts. These three blocks were combined by clonging into the expression vector pAA41, thereby forming the TNF gene intracellular expression plasmid, 


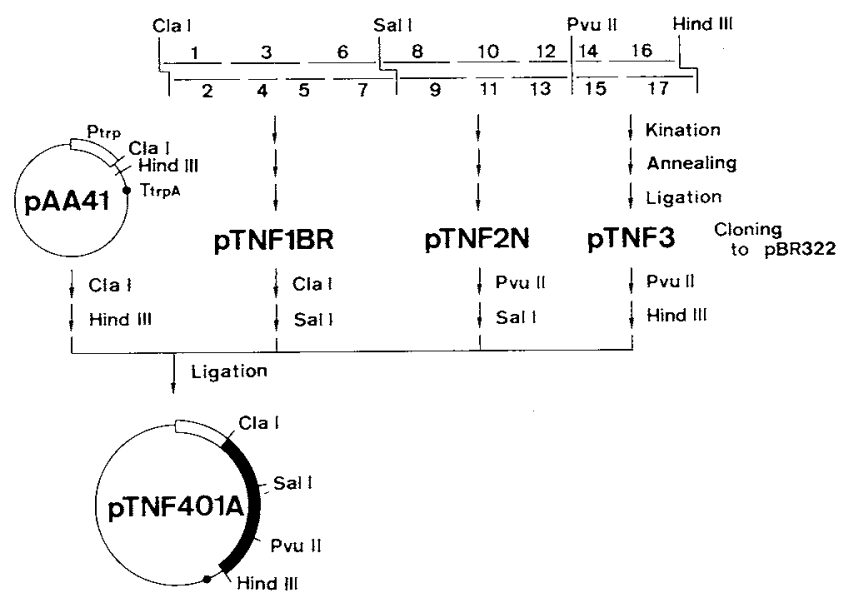

Fig. 2. Construction of an Intracellular Expression Plasmid.

The phosphorylated oligonucleotides were annealed and ligated to prepare pTNF1BR, pTNF2N, and pTNF3. The ClaI-SalI fragment of pTNF1BR, the SalI-PvulI fragment of pTNF2N, and the PvuII-HindIII fragment of pTNF3 were ligated and inserted between the Clal and HindIII sites of pAA41 to create an intracellular expression plasmid, pTNF401A.

pTNF401A (Fig. 2).

From SDS-PAGE and immunoblotting analysis of the lysate of $E$. coli $\mathrm{C} 600 \mathrm{r}^{-} \mathrm{m}^{-}$ carrying pTNF401A (E. coli C600r $\mathrm{r}^{-}$[pTN F401A]), it was demonstrated that TNF was produced in soluble form within the $E$. coli cells. Densitometric studies indicated that the quantity of TNF produced intracellularly by E. coli (hereinafter referred to as cytoplasmic TNF) accounted for as much as $20 \%$ of the total soluble protein constituents of the $E$. coli cells. Also, investigation of the in vitro antitumor activity of $E$. coli lysates containing cytoplasmic TNF yielded positive results (data not shown).

Construction of extracellular expression plasmids and extracellular production of TNF

Homology searches between human TNF and human lymphotoxin ${ }^{2)}$ suggest that the $\mathrm{N}$-terminus of TNF is not directly involved in its antitumor activity. In fact, N $\triangle 2-\mathrm{TNF}$ and N 47 -TNF produced intracellularly by $E$. coli have antitumor activity. ${ }^{3,4,20,21)}$ Moreover, mature human TNF protein is encoded by a region extending into both exons- 3 and -4 in the genomic TNF gene, ${ }^{22)}$ but the greater part (starting from Ala-18) is encoded by exon-4, and the functions of this portion are of principal interest. On the other hand, the signal peptide of the penicillinase produced by the alkalophilic Bacillus sp. No. 170 strain used in this study would be expected to be cleaved most efficiently when the $\mathrm{N}$-terminus of the mature protein is a serine residue (the $\mathrm{N}$-terminus of mature penicillinase protein is serine ${ }^{23)}$ ). In view of the foregoing considerations, the intracellular bacterial expression plasmid, pTNF401A, was used as a starting material, and extracellular expression plasmids encoding fused proteins containing wild-type TNF, N $42-T N F, N \Delta 7-T N F$, and N $117-T N F$ downstream to the penicillinase signal peptide were constructed. Figure 3 shows the methods for the construction of these plasmids.

$E$. coli HB101 strain cells transformed with the extracellular expression plasmids or the vector plasmid pEAP8 were cultivated, and the extracellular, periplasmic, and cytoplasmic fractions were collected. Immunoblotting analysis of each fraction was done (Fig. 4). The extracellular fraction of $E$ coli HB101 [pEXTNF3] showed a band believed to represent mature mutant $\mathrm{TNF}$, while the cytoplasmic fraction showed a band corresponding to the precursor of the mutant TNF. 
A

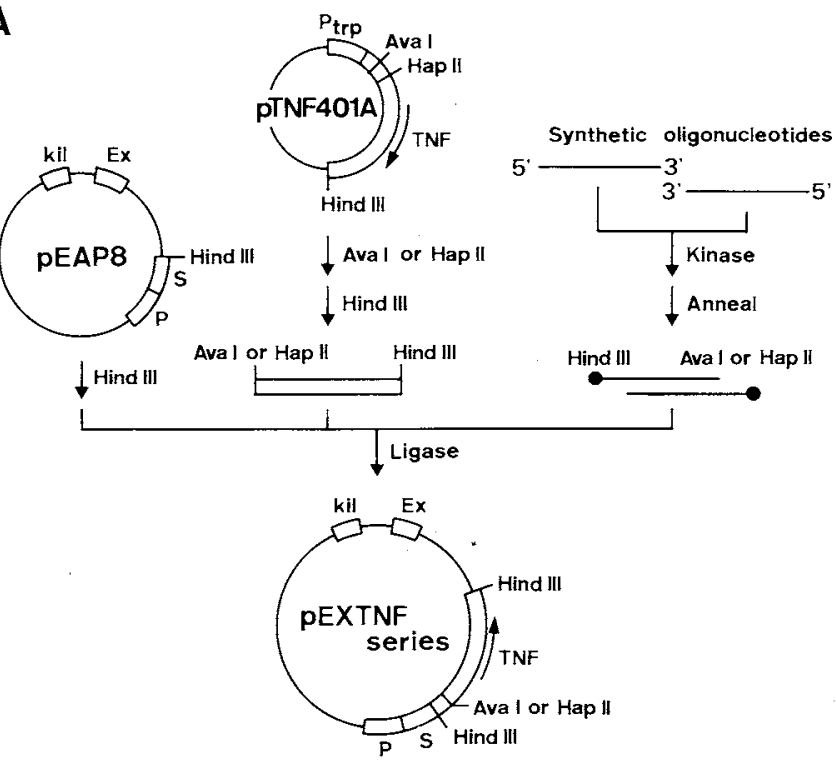

B

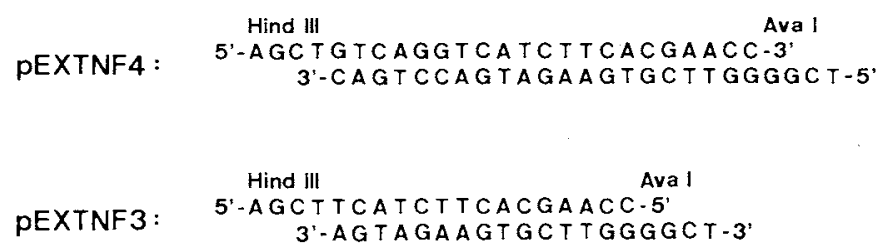

PEXTNF2 :

5ind III - AGCTGCAAACCCTCAAGCTGAGGGGCAGCTCCAGTGGCTGAACCGC-3' 3. CGTTTGGGAGTTCGACTCCCCGTCGAGGTCACCGACTTGGCGGC -5.

Fig. 3. Construction of Extracellular Expression Plasmids (A) and DNA Sequences of Synthetic Oligonucleotides Used (B).

The plasmis pTNF401A was digested with AvaI (for pEXTNF4 and pEXTNF3) or HapII (for pEXTNF2), and HindIII to obtain a TNF-gene-containing fragment. Oligonucleotides were kinated, annealed, and used as linkers. The DNA fragments containing the TNF gene and synthetic oligonucleotides were ligated and cloned into the HindIII site of pEAP8 to construct pEXTNF4, pEXTNF3, and pEXTNF2. Moreover, pEAP8 was digested with HindIII and filled in with Klenow fragment to obtain a linear pEAP8 fragment with flush ends. The TNF-gene-containing AvaI-HindIII fragment cleaved from pTNF401A was also filled in with Klenow fragment and then ligated with the linear pEAP8 fragment to construct pEXTNF1. Ex, Ex promoter; kil, kil gene; $\mathrm{P}$, penicillinase promoter region; $\mathrm{S}$, penicillinase signal peptide coding region; $\mathrm{P}_{\text {trp }}$, tryptophan operon promoter region.

In this clone, the excretion efficiency was estimated about $85 \%$ of total TNF mutant protein by measuring the density of the appropriate product band on a nitrocellulose filter. The cytoplasmic fraction of $E$. coli
HB101[pEXTNF1] also showed a band of the precursor of the mutant TNF, although no band was detected in the periplasmic and extracellular fractions. The fractions of the other clones showed no remarkable band in 
$\begin{array}{llllllllll}1 & 2 & 3 & 4 & 5 & 6 & 7 & 8 & 9 & 10\end{array}$

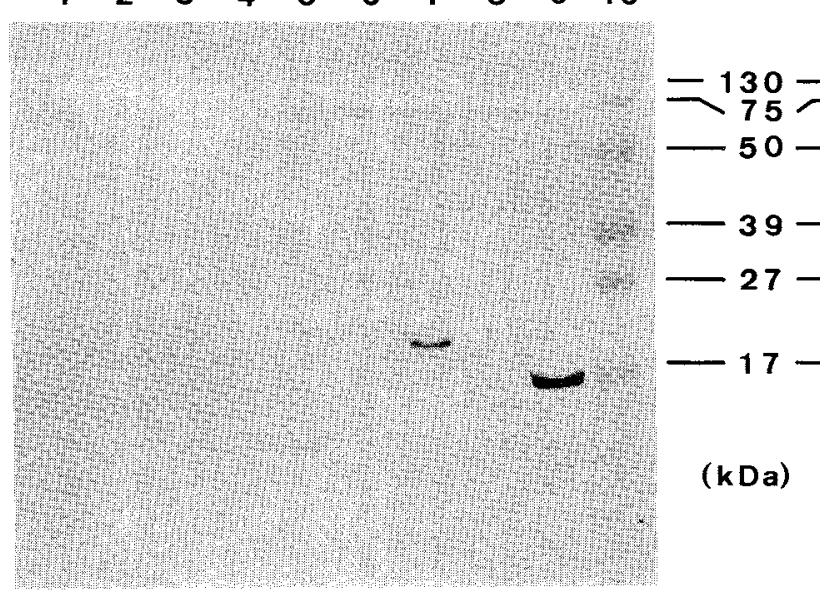

$\begin{array}{llllllll}11 & 12 & 13 & 14 & 15 & 16 & 17 & 18\end{array}$

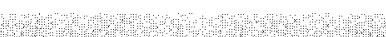

Fig. 4. Immunoblotting Analysis of Expressed TNF.

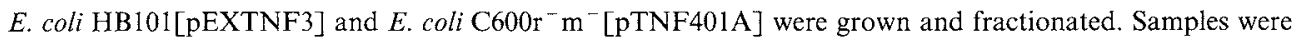
electrophoresed by $15 \%$ SDS-PAGE in the presence of 2-mercaptoethanol and assayed immunologically. Lane 1, cytoplasmic fraction of E. coli HB101[pEAP8]; lane 2, periplasmic fraction of $E$. coli HB101[pEAP8]; lane 3, extracellular fraction of $E$. coli HB101[pEAP8]; lane 4, cytoplasmic fraction of $E$. coli HB101[pEXTNF4]; lane 5, periplasmic fraction of E. coli HB101[pEXTNF4]; lane 6, extracellular fraction of E. coli HB101[pEXTNF4]; lane 7, cytoplasmic fraction of E. coli HB101[pEXTNF3]; lane 8, periplasmic fraction of E. coli HB101[pEXTNF3]; lane 9, extracellular fraction of E. coli HB101[pEXTNF3]; lane 10 and 12, prestained molecular weight marker (Bio-Rad); lane 11, cytoplasmic fraction of $E$. coli C600 $\mathrm{r}^{-} \mathrm{m}^{-}$[pTNF401A]; lane 13, cytoplasmic fraction of E. coli HB101[pEXTNF1]; lane 14, periplasmic fraction of E. coli HB101[pEXTNF1]; lane 15, extracellular fraction of $E$. coli HB101[pEXTNF1]; lane 16, cytoplasmic fraction of E. coli HB101[pEXTNF2]; lane 17, periplasmic fraction of E. coli HB101 [pEXTNF2]; lane 18, extracellular fraction of E. coli HB101[pEXTNF2]. Each sample corresponds to $300 \mu$ of the original culture.

Table I. DISTRIBUTION OF TNF EXPRESSED IN E. coli ${ }^{a}$

\begin{tabular}{|c|c|c|c|c|}
\hline \multirow[b]{2}{*}{ Plasmid } & \multirow{2}{*}{$\begin{array}{l}\text { TNF coded } \\
\text { (N-terminal } \\
\text { amino acid) }\end{array}$} & \multicolumn{3}{|c|}{ Activity in Each fraction $(\mathrm{U} / \mathrm{ml})$} \\
\hline & & $\begin{array}{c}\text { Cytoplasmic } \\
(\%)\end{array}$ & $\begin{array}{l}\text { Periplasmic } \\
(\%)\end{array}$ & $\begin{array}{c}\text { Extracellular } \\
(\%)\end{array}$ \\
\hline pEAP8 & - & 0 & 0 & 0 \\
\hline & $(-)$ & $(-)$ & $(-)$ & $(-)$ \\
\hline pEXTNF4 & $\begin{array}{l}\text { Wild-type } \\
\text { (Val) }\end{array}$ & $\begin{array}{l}1,700 \\
(14.1)\end{array}$ & $\begin{array}{l}2,000 \\
(16.6)\end{array}$ & $\begin{array}{l}8,310 \\
(69.3)\end{array}$ \\
\hline pEXTNF3 & $\begin{array}{l}\mathrm{N} \Delta 2 \\
\text { (Ser) }\end{array}$ & $\begin{array}{r}8,710 \\
(4.6)\end{array}$ & $\begin{array}{r}15.100 \\
(8.0)\end{array}$ & $\begin{array}{r}166,000 \\
(87.4)\end{array}$ \\
\hline pEXTNF1 & $\begin{array}{l}\text { N } \Delta 7 \\
\text { (Pro) }\end{array}$ & $\begin{array}{c}648 \\
(85.9)\end{array}$ & $\begin{array}{c}31 \\
(4.1)\end{array}$ & $\begin{array}{c}75 \\
(10.0)\end{array}$ \\
\hline pEXTNF2 & $\begin{array}{l}\text { N } \triangle 17 \\
\text { (Ala) }\end{array}$ & $\begin{array}{c}0 \\
(-)\end{array}$ & $\begin{array}{c}0 \\
(-)\end{array}$ & $\begin{array}{c}0 \\
(-)\end{array}$ \\
\hline
\end{tabular}

a Amount of TNF in each fraction is shown as in vitro antitumor activity.

immunoblotting analysis. Table I shows the distribution of in vitro antitumor activity in the fractions. In vitro antitumor activity was shown by the culture supernatants from those transformed with pEXTNF3, pEXTNF4, and pEXTNF1, demonstrating that excretion of TNF with the various $\mathrm{N}$-terminal deletions did occur in the $E$. coli carrying these plasmids. 
The results shown in Fig. 4 and Table I indicate that $E$. coli HB101[pEXTNF3] was the most effective among these various clones. In $E$. coli HB101[pEXTNF3], about $85 \%$ of the mutant TNF protein and nearly $90 \%$ of the antitumor activity were detected in the extracellular fraction, and according to the ELISA results, $8.6 \mathrm{mg}$ of the mutant TNF per liter of culture was produced extracellularly by this clone. The various properties of the mutant TNF excreted by $E$. coli $\mathrm{HB} 101$ [pEXTNF3] were investigate$\mathrm{d}$ in subsequent experiments.

\section{Physicochemical properties of recombinant TNFs}

The cytoplasmic TNF was purified from the lysate of $E$. coli $\mathrm{C} 600 \mathrm{r}^{-} \mathrm{m}^{-}[\mathrm{p}$ TNF401A] by affinity chromatography using anti-human TNF monoclonal antibody. The relative molecular mass $\left(M_{r}\right)$ of the cytoplasmic TNF as indicated by SDS-PAGE was approximately 17 kirodaltons $(\mathrm{kDa})$ (data not shown), which agrees well with the $M_{r}$ of 17,356 daltons inferred from the primary structure of the sequence of 157 amino acid residues. On the other hand, after gel filtration, a substance was eluted at the position corresponding to an $M_{r}$ of about $30-35 \mathrm{kDa}$, suggesting that the cytoplasmic TNF assumes an oligomeric form in solution. Also, investigation of the amino acid sequence in the vicinity of the $\mathrm{N}$-terminus of the cytoplasmic TNF found three species of TNF molecules; that is, one retaining the terminal methionine residue originating from the initiation codon, a second from which this methionine residue had been cleaved off, and a third lacking the two last residues at the $\mathrm{N}$-terminus. The third molecular species is believed to arise from the action of proteases present in $E$. coli cells. The proportion of this species could be reduced by adding protease inhibitors during the purification process, but in any case, it was shown that the N-termini of the cytoplasmic TNF were not uniform.

The mutant TNF was also purified by affinity chromatography from culture supernates of $E$. coli HB101[pEXTNF3]. The $M_{r}$ of the $E$. coli-excreted mutant TNF as measured by
SDS-PAGE was approximately $17 \mathrm{kDa}$, as compared with approximately $35-40 \mathrm{kDa}$ by gel filtration (data not shown), indicating, as in the case of cytoplasmic TNF, a strong possibility that this mutant TNF assumes an oligomeric form in solution. The N-terminal amino acid sequence of the mutant TNF excreted by $E$. coli was $\mathrm{H}_{2} \mathrm{~N}$-Ser-Ser-Ser-ArgThr-Pro-SerAsp-. This showed that the signal peptide was properly cleaved during the process of excretion, and that mature protein in the form of N/2-TNF was extracellularly excreted as anticipated. The amino acid composition of the mutant TNF excreted by $E$. coli (hereinafter referred to as excreted $\mathrm{N} \triangle 2-\mathrm{TNF}$ ) was mostly consistent with that calculated from the DNA sequence (data not shown).

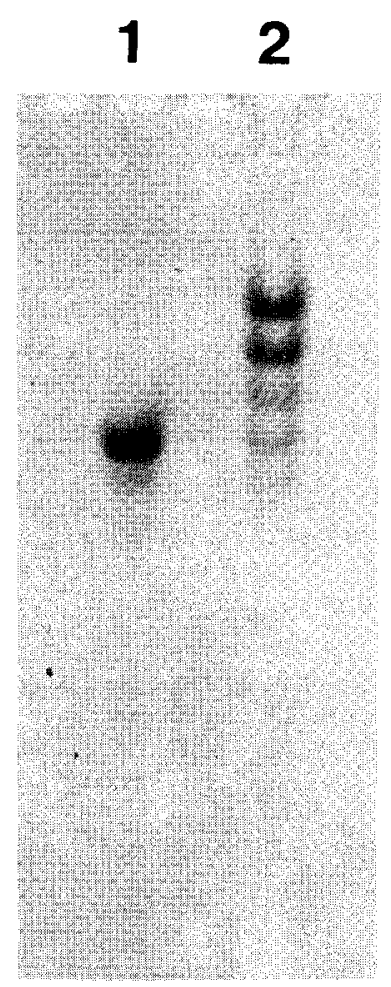

Fig. 5. Native-PAGE Analysis of Cytoplasmic TNF and Excreted N42-TNF.

Native 4-15\% polyacrylamide gel electrophoresis was done, and the gel was stained with Coomassie Brilliant Blue R-250. Lane 1, excreted N42-TNF from $E$. coli HB101[pEXTNF3]; lane 2, cytoplasmic TNF from $E$. coli C600 ${ }^{-} \mathrm{m}^{-}$[pTNF40IA]. About $10 \mu \mathrm{g}$ of purified TNF was put on each lane. 
Figure 5 shows the results of native-PAGE of cytoplasmic TNF and excreted NA2-TNF. Cytoplasmic TNF had a multiplicity of at least 4 to 5 bands, but the pattern for excreted N42-TNF consisted of nearly just a single band. Moreover, in isoelectric focusing (IEF), cytoplasmic TNF displayed several bands in the region of $\mathrm{pH} 5.4-6.5$, while the band pattern of excreted N $12-\mathrm{TNF}$ was almost entirely concentrated at the position corresponding to $\mathrm{pH} 5.7$ (data not shown). This again demonstrated that cytoplasmic TNF is not uniform in composition, while excreted N $\Delta 2$ TNF has a nearly uniform composition, consisting almost entirely of N $\triangle 2-T N F$.

\section{Biological activities of recombinant TNFs}

The in vitro antitumor activities of purified cytoplasmic TNF and excreted N $\Delta 2-T N F$ are

Table II. SPECIFIC ACtivity OF Cytoplasmic TNF, CYTOPLASMIC NA2-TNF AND EXCRETED N42-TNF

\begin{tabular}{lcc}
\hline TNF & $\begin{array}{c}\text { Specific } \\
\text { activity }^{a} \\
(\mathrm{U} / \mathrm{mg})\end{array}$ & Ratio \\
\hline Cytoplasmic TNF & $1.4 \times 10^{7}$ & 1.0 \\
Cytoplasmic N $\Delta 2-\mathrm{TNF}$ & $1.8 \times 10^{7}$ & 1.3 \\
Excreted N $\Delta 2-\mathrm{TNF}$ & $3.3 \times 10^{7}$ & 2.4
\end{tabular}

a In vitro antitumor activity to murine $\mathrm{L}, 929$ cells in the presence of actinomycin D in $18 \mathrm{hr}$. Each assay was done in triplicate, and the average of six independent assays are shown.

Table III. Necrosis of Meth A SARcoma Caused in vivo BY CYTOPLASMIC TNF, CYTOPLASMIC N/2-TNF AND EXCRETED N/2-TNF

\begin{tabular}{|c|c|c|c|c|c|}
\hline \multirow{3}{*}{ TNF } & \multirow{3}{*}{$\begin{array}{c}\text { Dose } \\
(\mu \mathrm{g} / \\
\text { mouse })\end{array}$} & \multicolumn{4}{|c|}{ Necrotic response ${ }^{a}$} \\
\hline & & - & + & ++ & +++ \\
\hline & & \multicolumn{4}{|c|}{ Number of mice } \\
\hline Saline & - & 5 & 0 & 0 & 0 \\
\hline Cytoplasmic TNF & 10 & 0 & 5 & 2 & 0 \\
\hline Cytoplasmic N $42-\mathrm{TNF}$ & 10 & 0 & 2 & 1 & 0 \\
\hline Excreted N$\triangle 2-T N F$ & 10 & 0 & 1 & 3 & 4 \\
\hline
\end{tabular}

a Tumor necrosis was assessed as follows ${ }^{1)}$ : (-) no change, $(+)$ slight necrosis, $(++)$ moderate necrosis, $(+++)$ extensive necrosis. shown in Table II. Excreted N42-TNF had 2.4 times higher specific activity than cytoplasmic TNF. Furthermore, the intracellular expression plasmid pTNF428A encoding N/2-TNF was derived from the plasmid pTNF401A using suitable synthetic oligonucleotides as described previously. ${ }^{21)}$ Cytoplasmic N/2-TNF was purified from the lysate of E. coli $\mathrm{C} 600 \mathrm{r}^{-} \mathrm{m}^{-}$ [pTNF428A] and its in vitro antitumor activity was measured. The specific activity of cytoplasmic N $\triangle 2-\mathrm{TNF}$ was only half as much as that of excreted N/2-TNF, although cytoplasmic N $42-\mathrm{TNF}$ had 1.3 times higher specific activity than cytoplasmic TNF.

Ten-micrograms intravenous doses of purified excreted N $\Delta 2-\mathrm{TNF}$, cytoplasmic TNF or cytoplasmic N $\triangle 2-T N F$ were administered to mice with transplanted Meth A sarcoma. The resulting degrees of hemorrhagic necrosis are shown in Table III. These results demonstrate that excreted N12-TNF has higher antitumor activity than cytoplasmic TNF and cytoplasmic N $42-\mathrm{TNF}$, not only in vitro but in vivo as well.

\section{Discussion}

An approximately 490-bp DNA fragment encoding human TNF was synthesized chemically. The synthesized TNF gene was designed to facilitate cloning into an expression vector and subsequent genetic modification. An intracellular expression plasmid was constructed by introducing this TNF gene into an expression vector. $E$. coli $\mathrm{C} 600 \mathrm{r}^{-} \mathrm{m}^{-}$transformed with pTNF401A produced TNF in the cytoplasm in the form of a soluble protein, and this TNF reached $20 \%$ of the total soluble protein in the cell.

Also, several varieties of plasmids for extracellular expression of the TNF gene with $\mathrm{N}$-terminal deletions were constructed by introducing synthetic TNF genes into an extracellular expression vector. $E$. coli $\mathrm{HB} 101$ with a plasmid pEXTNF2 encoding NA17TNF had no detectable antitumor activity. The gene product also could not detected by immunoblotting analysis in the this clone; 
therefore, detailed discussion in this case is difficult. Antitumor activity was detected in the culture supernatant of $E$. coli HB101 transformed with extracellular expression plasmids other than pEXTNF2. The productivity was low for E. coli HB101 with a plasmid pEXTNF4 encoding wild-type TNF, and the excretion efficiency of this clone could not be estimated due to its low productivity. A thick band corresponding to the precursor form of mutant TNF was detected in the cytoplasmic fraction of $E$. coli $\mathrm{HB} 101$ with a plasmid pEXTNF1 encoding N $\triangle 7-T N F$, but not in the periplasmic and extracellular fractions, suggesting the low excretion efficiency of this clone. On the other hand; E. coli HB101 transformed with plasmids pEXTNF3 encoding N $42-T N F$ was found to produce large quantities of precursor mutant TNF, and about $85 \%$ of the mutant TNF protein produced was excreted. About $90 \%$ of the antitumor activity was detected in the extracellular fraction in this clone. The amino acid sequence of N $\Delta 2-\mathrm{TNF}$ commences with an $\mathrm{N}$-terminal serine residue, as does the mature penicilinase protein, suggesting that the signal peptide is more readily cleaved in this clone. Furthermore, we constructed the extracellular expression plasmid pEXTNF9 encoding N $44-T N F$, which had a serine residue at the $\mathrm{N}$-terminus. Also in $E$. coli HB101[pEXTNF9], about $75 \%$ of the antitumor activity was detected in the extracellular fraction. In the case of $E$. coli HB101[pEXTNF3], more than $95 \%$ of the antitumor activity was detected in the periplasmic and extracellular fractions, although $15 \%$ of (precursor) mutant TNF was retained in the cytoplasm. It appears to be due to the low specific activity of precursor mutant TNF compared with mature N $\triangle 2-\mathrm{TNF}$ in periplasmic and extracellular fractions. The other discrepancy between the density of bands in immunoblotting analysis and antitumor activity might be also due to the difference of specific activity of each (precursor) mutant TNF species.

The N-terminus of cytoplasmic TNF was not uniform, and even as regards the amino acid sequence alone, a mixture of three different molecular species was present. When electrophoresed by native-PAGE and IEF, this cytoplasmic TNF formed about 5-8 bands. This diversity in the composition of the cytoplasmic TNF may be due not only to variations in the $\mathrm{N}$-terminal amino acid sequence but possibly also to factors such as variations in oligomer formation and modification of amino acid side chains. On the other hand, excreted N/2-TNF is more uniform than cytoplasmic TNF. The amino acids at the $\mathrm{N}$-termini of a portion of the cytoplasmic TNF are cleaved by proteases, but since excreted N $42-T N F$ lacks the two $\mathrm{N}$-terminal amino acids $a b$ initio, this molecule is less susceptible to the effects of proteases. Moreover, the effects of intracellular proteases can also be avoided by inducing extracellular excretion. ${ }^{9)}$ Therefore, the uniformity of excreted $\mathrm{N} \Delta 2-\mathrm{TNF}$ appears to be synergistically elevated. Regarding the molecular mass calculated from the elution pattern of gel filtration, the results for excreted N $\triangle 2-\mathrm{TNF}$ were in the range of $35-40 \mathrm{kDa}$, compared with the slightly lower range of $30-35 \mathrm{kDa}$ for cytoplasmic TNF. Recent reports have stated that human TNF assumes a compact trimeric structure in aqueous solutions. ${ }^{24,25)}$ Perhaps the excreted N $\triangle 2-T N F$ and cytoplasmic TNF molecules are packed in different ways when forming trimers.

Excreted N/2-TNF had higher antitumor activity both in vitro and in vivo than cytoplasmic TNF cytoplasmic N $\triangle 2-\mathrm{TNF}$. The higher antitumor activity of excreted N $\triangle 2$ TNF cannot be explained solely on the basis of deletion of the two N-terminal amino acids, and appears to be largely due to some optimization of the tertiary structure during the process of excretion. Further studies are under way to define the tertiary structure of excreted N $\triangle 2-\mathrm{TNF}$ by NMR and X-ray crystallography.

Acknowledgments. We wish to thank Noriyuki Tsunekawa and Fumitaka Miyagi of Teijin Limited for their contribution to the amino acid sequencing and amino acid analysis. 


\section{References}

1) E. A. Carswell, L. J. Old, R. L. Kassel, S. Green, N. Fiore and B. Williamson, Proc. Natl. Acad. Sci. U.S.A., 72, 3666 (1975).

2) D. Pennica, G. E. Nedwin, J. S. Hayflick, P. H. Seburg, R. Derynck, M. A. Palladino, W. J. Kohr, B. B. Aggarwal and D. V. Goeddel, Nature (London), 312, 724 (1984).

3) T. Shirai, H. Yamaguchi, H. Ito, C. W. Tod and D. V. Goeddel, Nature (London), 313, 803 (1985).

4) M. Yamada, Y. Furutani, M. Notake, J. Yamaguchi, M. Yamayoshi, T. Fukui, H. Nomura, M. Komiya, J. Kuwashima, K. Nakano, Y. Sohmura and S. Nakamura, J. Biotechnol., 3, 141 (1985).

5) A. M. Wang, A. A. Creasey, M. B. Lander, L. S. Lin, J. Stricker, J. N. van Arsdell, R. Yamamoto and D. F. Mark, Science, 228, 149 (1985).

6) A. Marmenout, L. Fransen, J. Tavernier, J. van der Heyden, R. Tizard, E. Kawashima, A. Shaw, M.-J. Johnson, D. Semon, R. Muller, M.-R. Ruysschaert, A. van Vliet and W. Fiers, Eur. J. Biochem., 152, 515 (1985).

7) K. Haranaka, Biomedica, 3, 343 (1988).

8) L. J. Old, Science, 230, 630 (1985).

9) K. Kitai, T. Kudo, S. Nakamura, T. Masegi, Y. Ichikawa and K. Horikoshi, Appl. Microbiol. Biotechnol., 28, 52 (1988).

10) S. Nakamura, T. Masegi, K. Kitai, A. Kudo, T. Watanabe and Y. Ichikawa, J. Biotechnol., 8, 141 (1988).

11) T. Masegi, S. Nakamura, K. Kitai and Y. Ichikawa, Agric. Biol. Chem., 52, 1609 (1988).

12) H. Matsuda, S. Nakamura, Y. Ichikawa, K. Kozai,
R. Takano, M. Nose, S. Endo, Y. Nishimura and Y. Arata, Molec. Immunol., 27, 571 (1990).

13) C. Kato, T. Kobayashi, T. Kudo, T. Furusato, Y. Murakami, T. Tanaka, H. Baba, T. Oishi, E. Otsuka, M. Ikehara, T. Yanagida, H. Kato, S. Moriyama and K. Horikoshi, Gene, 54, 197 (1987).

14) T. Maniatis, E. F. Fritsch and J. Samabrook, "Molecular Cloning: A Laboratory Manual," Cold Spring Harbor Laboratory, New York, 1982.

15) U. K. Laemmli, Nature (London), 227, 680 (1970).

16) W. W. Burnette, Anal. Biochem., 112, 195 (1981).

17) K. Yone, J. Suzuki, N. Tsunekawa, Y. Ichikawa and S. Furukawa, Immunobiol., 175, 106 (1987).

18) M. R. Ruff and G. E. Gifford, J. Immunol, 125, 1671 (1980).

19) L. J. Old, E. A. Boyse, D. A. Clarke and E. A. Carswell, Ann. N. Y. Acad. Sci., 101, 80 (1962).

20) A. A. Creasey, L. V. Doyle, M. T. Reynolds, T. Jung, L. S. Lin and C. R. Vitt, Cancer Res., 47, 145(1987).

21) S. Nakamura, T. Masegi, M. Fukuoka, K. Kitai, A. Kato, Y. Ichikawa, N. Watanabe and Y. Niitsu, Biotherapy, 4, 520 (1990).

22) S. A. Nedospasov, A. N. Shakhov, R. H. Turetskaya, V. A. Mett, M. M. Azizov, G. P. Georgiev, V. G. Korobko, V. N. Dobrynin, S. A. Filippov, N. S. Bystrov, E. F. Boldyreva and Y. A. Ovchinnikov, Cold Spring Harbor Symposium, Quant. Biol., 51, 597 (1986).

23) C. Kato, T. Kudo, K. Watanabe and K. Horikoshi, J. Gen. Microbiol., 131, 3317 (1985).

24) P. Wingfield, R. H. Pain and S. Craig, FEBS Lett., 211, 179 (1987).

25) R. A. Smith and C. Baglioni, J. Biol. Chem., 262, 6951 (1987). 